\title{
The natural history of impaired glucose tolerance in the Micronesian population of Nauru: A six-year follow-up study
}

\author{
H. King, P.Zimmet, L. R. Raper and B. Balkau \\ WHO Collaborating Centre for the Epidemiology of Diabetes Mellitus, Royal Southern Memorial Hospital, Melbourne, Australia
}

\begin{abstract}
Summary. A longitudinal study of 266 randomly selected nondiabetic Nauruans (215 normal subjects, 51 with impaired glucose tolerance) has permitted the natural history of impaired glucose tolerance to be studied in this Micronesian population. Nauruans are known to suffer from a very high prevalence of abnormal glucose tolerance. The subjects were first examined in 1975-1976, and a follow-up examination was performed in 1982. Of the subjects with impaired glucose tolerance, $26 \%$ developed diabetes during the study period ( $4 \%$ per annum) compared with $7 \%$ of normal subjects ( $1 \%$ per annum). After controlling for the effects of both age and obesity, the risk of subsequent diabetes for subjects with impaired glucose tolerance remained significantly higher than for normal subjects (odds ratio 3.6, 95\% confidence interval 1.4-9.1). Of those with impaired glucose tolerance on initial examination, $39 \%$ were normoglycaemic at follow-up. In subjects with impaired glucose tolerance, of nine factors examined only plas-
\end{abstract}

ma glucose concentration at the time of the initial examination was consistent in predicting progression to diabetes, when the data were examined by both univariate and multivariate methods. Both 2 -h and fasting plasma glucose values were useful predictors. Thus, Nauruans with impaired glucose tolerance have a higher risk of subsequent diabetes than their normoglycaemic counterparts, after controlling for age and obesity. Nevertheless, the prognosis of impaired glucose tolerance is unpredictable as a substantial proportion of such subjects return to normality. Plasma glucose concentration is the most important predictor of subsequent diabetes. These results accord with recent findings from longitudinal studies of impaired glucose tolerance in other populations.

Key words: Impaired glucose tolerance, natural history, plasma glucose concentration, Nauru.
In 1982, a follow-up diabetes survey of the Micronesian population of Nauru was conducted. The initial examination had been in 1975-1976, and the average length of time between examinations was 6.2 years.

Of the 266 subjects examined in both surveys who were initially non-diabetic, 215 were normoglycaemic and 51 had impaired glucose tolerance at first examination. This report examines the prognosis of those with impaired glucose tolerance, and assesses the predictive power of selected variables in relation to the subsequent development of diabetes. The findings are compared with similar data from other populations, in an attempt to shed further light on the validity of the intermediate category of glucose tolerance, and in response to the call from the World Health Organization Expert Committee on Diabetes [1] for further population-based evidence concerning the present diagnostic criteria for glucose intolerance.

\section{Subjects and methods}

\section{Background}

Nauru is a small, isolated island in the Central Pacific, lying $60 \mathrm{~km}$ south of the equator. The island is $20 \mathrm{~km}$ in circumference. The indigenous population of approximately 4000 persons is of predominantly Micronesian ancestry. The discovery and subsequent exploitation of large deposits of phosphate on the island has lead to affiuence and to a high degree of urbanization since the Republic of Nauru achieved independence in 1968 . The prevalence of obesity is high, few subjects engage in heavy physical activity, and large quantities of imported food and drink are consumed by the islanders [2]. It has been demonstrated that Nauruans now suffer from a very high prevalence of Type 2 (non-insulin-dependent) diabetes [3-5].

\section{Subjects}

A diabetes survey of all adult Nauruan residents of a randomly selected region of Nauru (a homogeneous island with respect to lifestyle) was conducted, in two stages. The first was in May 1975, and the sec- 
ond in January 1976. The findings of this initial survey have already been published [3, 4]. In January 1982, a diabetes survey of the whole adult Nauruan population was performed [5]. Of the 456 persons examined in 1975 who were still resident in Nauru in 1982, and who were eligible to attend the second survey (being present on the island, and not too infirm to reach the survey site), 366 did so, giving a response rate of $80 \%$ at follow-up. Of these, 266 persons were non-diabetic on initial examination, and these form the basis of the present study.

\section{Methods}

Survey methods were standardized in the two surveys. Selection procedures and survey methodology have been described in detail elsewhere [3-5].

All subjects were examined at a central survey site after fasting overnight, and the glucose load of $75 \mathrm{~g}$ was given orally. Fasting and $2-\mathrm{h}$ venous blood samples were taken at the survey site. Plasma glucose was measured on a Yellow Springs Instrument glucose analyser using a glucose oxidase method. Plasma cholesterol, triglycerides and urinary creatinine concentrations were measured on samples frozen on collection and transported to Melbourne, Australia. Blood pressure was measured with the subject in the sitting position. Height, weight, and triceps skinfold thickness were recorded, and body mass index was calculated as weight $(\mathrm{kg})$ divided by the square of height (meters). History of cigarette consumption and family history of disease were recorded for each individual.

\section{Criteria for abnormal glucose tolerance}

Abnormal glucose tolerance was classified in accordance with a modification of current WHO and National Diabetes Data Group criteria suited to field survey conditions $[1,6]$, diabetes mellitus being diagnosed on the basis of a 2-h plasma glucose concentration of $11.1 \mathrm{mmol} / 1$ or greater, $2 \mathrm{~h}$ after a $75 \mathrm{~g}$ oral glucose load. Impaired glucose tolerance was defined by a 2 -h plasma glucose concentration greater or equal to $7.8 \mathrm{mmol} / \mathrm{l}$, but $<11.1 \mathrm{mmol} / \mathrm{l}$. All previously known diabetic subjects were included in the diabetic category. Subjects not fulfilling these criteria were considered to have normal glucose tolerance.

\section{Results}

The age distribution of the 266 subjects with normal and impaired glucose tolerance at initial examination is shown in Table 1 (decade, rather than mid-decade intervals were used for consistency with earlier reports). It is evident that subjects with impaired glucose tolerance formed an older population than the normal subjects in both sexes, and the effect of age was taken into account when assessing characteristics associated with progression to diabetes.

\section{Crude prognosis of impaired glucose tolerance}

The mean time interval between examinations was 6.2 years. A comparison of the percentage of subjects in each category of glucose tolerance at follow-up within each baseline group (normal or impaired glucose tolerance) is shown in Table 2 . Of the 51 subjects with impaired glucose tolerance, $13(26 \%)$ progressed to diabetes (men $27 \%$; women $24 \%$ ), compared with $14(7 \%)$ of the 215 normal subjects (men 7\%, women 6\%). The
Table 1. Distribution of the 266 subjects by age and diabetic status at initial examination

\begin{tabular}{|c|c|c|c|c|}
\hline \multirow[t]{3}{*}{ Age (years) } & \multicolumn{4}{|c|}{ Diabetic status in $1975-1976$} \\
\hline & \multicolumn{2}{|l|}{ Normal } & \multicolumn{2}{|c|}{$\begin{array}{l}\text { Impaired glucose } \\
\text { tolerance }\end{array}$} \\
\hline & Number & $\%$ of total & Number & $\%$ of total \\
\hline \multicolumn{5}{|l|}{ Males } \\
\hline $0-19$ & 26 & 27 & 2 & 9 \\
\hline $20-29$ & 38 & 40 & 7 & 32 \\
\hline $30-39$ & 14 & 15 & 3 & 14 \\
\hline $40-49$ & 15 & 16 & 6 & 27 \\
\hline $50-59$ & 3 & 3 & 2 & 9 \\
\hline $60+$ & 0 & 0 & 2 & 9 \\
\hline Total & 96 & 100 & 22 & 100 \\
\hline \multicolumn{5}{|l|}{ Females } \\
\hline $0-19$ & 42 & 35 & 2 & 7 \\
\hline $20-29$ & 43 & 36 & 8 & 28 \\
\hline $30-39$ & 16 & 14 & 6 & 21 \\
\hline $40-49$ & 11 & 9 & 10 & 35 \\
\hline $50-59$ & 6 & 5 & 3 & 10 \\
\hline $60+$ & 1 & 1 & 0 & 0 \\
\hline Total & 119 & 100 & 29 & 100 \\
\hline
\end{tabular}

Table 2. Comparison of diabetic status of Nauruan non-diabetics in 1975-1976 and follow-up status in 1982

\begin{tabular}{|c|c|c|c|c|}
\hline \multirow{2}{*}{$\begin{array}{l}\text { Diabetic status } \\
\text { in } 1975-1976\end{array}$} & \multicolumn{4}{|c|}{ Diabetic status in 1982} \\
\hline & Normal & $\begin{array}{l}\text { Impaired } \\
\text { glucose } \\
\text { tolerance }\end{array}$ & Diabetic & Total \\
\hline \multicolumn{5}{|l|}{ Males } \\
\hline Normal & 72 & 17 & 7 & 96 \\
\hline $\begin{array}{l}\text { Impaired glucose } \\
\text { tolerance }\end{array}$ & 7 & 9 & 6 & 22 \\
\hline \multicolumn{5}{|l|}{ Females } \\
\hline Normal & 95 & 17 & 7 & 119 \\
\hline $\begin{array}{l}\text { Impaired glucose } \\
\text { tolerance }\end{array}$ & 13 & 9 & 7 & 29 \\
\hline \multicolumn{5}{|l|}{ Sexes combined } \\
\hline Normal & 167 & 34 & 14 & 215 \\
\hline $\begin{array}{l}\text { Impaired glucose } \\
\text { tolerance }\end{array}$ & 20 & 18 & 13 & 51 \\
\hline
\end{tabular}

crude incidence of diabetes was $4 \%$ per annum in the former (13 incident cases, 322 person years at risk). In the latter, the crude incidence of diabetes was $1 \%$ per annum (14 incident cases, 1339 person years at risk). Of those initially displaying impaired glucose tolerance, $35 \%$ retained this status, whereas 39\% were normoglycaemic at follow-up.

\section{The risk of impaired glucose tolerance after controlling for age and obesity}

To assess the risk attached to impaired glucose tolerance, in terms of subsequent diabetes, the multiple logistic regression model was used to predict progression to diabetes (Table 3 ). The predictor variables included in the model were: age, sex, body mass index, and pres- 
Table 3. Parameter estimates, standard errors, and standardized parameter estimates for selected baseline variables, derived from the multiple logistic regression model ${ }^{\mathrm{a}}$, predicting progression to diabetes $(n=264)^{\mathrm{b}}$

\begin{tabular}{lccc}
\hline Variable & $\begin{array}{l}\text { Parameter } \\
\text { estimate }\end{array}$ & $\begin{array}{l}\text { Standard } \\
\text { error }\end{array}$ & $\begin{array}{l}\text { Standard- } \\
\text { ized } \\
\text { parameter } \\
\text { estimate }\end{array}$ \\
\hline Age (years) & 0.32 & 0.14 & $2.3^{\mathrm{c}}$ \\
Age squared & $-4 \times 10^{-3}$ & $2 \times 10^{-3}$ & $-2.1^{\mathrm{c}}$ \\
Sex (female) & -0.51 & 0.46 & -1.1 \\
Date of first examination & -0.10 & 0.45 & -0.2 \\
Body mass index $\left(\mathrm{kg} / \mathrm{m}^{2}\right)$ & 0.09 & 0.03 & $2.5^{\mathrm{c}}$ \\
Impaired glucose tolerance & 1.40 & 0.47 & $3.0^{\mathrm{d}}$
\end{tabular}

${ }^{a}$ Log likelihood statistic: 140.3 on 257 degrees of freedom (see Results), ${ }^{\mathrm{b}}$ Two cases deleted due to missing data. ${ }^{\mathrm{c}} p<0.05 ;{ }^{\mathrm{d}} p<0.01$. The standardized parameter estimate may be referred to tables of the normal distribution as a test of significance of the parameter in the regression equation [8]

Table 4. Mean values of selected baseline variables in subjects not progressing, compared with those progressing to diabetes ${ }^{b}$

\begin{tabular}{lcc}
\hline Variable & $\begin{array}{l}\text { Not progressing } \\
\text { to diabetes } \\
(n=37)\end{array}$ & $\begin{array}{l}\text { Progressing } \\
\text { to diabetes } \\
(n=13)\end{array}$ \\
\hline Age (years) & 35.9 & 40.7 \\
2-h plasma glucose $(\mathrm{mmol} / \mathrm{l})$ & 8.6 & $9.5^{\mathrm{c}}$ \\
Fasting plasma glucose $(\mathrm{mmol} / \mathrm{l})$ & 5.6 & $6.4^{\mathrm{C}}$ \\
Body mass index $\left(\mathrm{kg} / \mathrm{m}^{2}\right)$ & 30.7 & $35.3^{\mathrm{c}}$ \\
Triceps skinfold thickness $(\mathrm{mm})$ & 25.8 & 31.5 \\
Plasma cholesterol $(\mathrm{mmol} / 1)$ & 5.3 & 5.3 \\
Plasma triglycerides $(\mathrm{mmol} / 1)$ & 1.3 & 1.6 \\
Plasma uric acid $(\mathrm{mmol} / \mathrm{l})$ & 0.4 & 0.4 \\
Systolic blood pressure $(\mathrm{mmHg})$ & 136 & 131 \\
Urinary creatinine (mmol/1) & 0.1 & 0.1 \\
\% cigarette smokers & 50.0 & 46.2 \\
\% positive family history of diabetes & 51.7 & 50.0
\end{tabular}

a Continuous variables standardized for age by analysis of covariance. ${ }^{b}$ Subjects with impaired glucose tolerance only ( $n=50$, one case deleted due to missing data). ${ }^{\mathrm{c}} p<0.01$ (F test)

ence or absence of impaired glucose tolerance at initial examination. A further dummy variable represented the date of original survey, to control for discrepancies in the period of follow-up. A squared term was included to account for a non-linear trend with age, as it significantly improved the fit of the model. The model fitted the data adequately, as demonstrated by the log likelihood statistic, which had a value of 140 on 256 degrees of freedom. This statistic has an approximately chisquared distribution on the given degrees of freedom [7]. The exponents of the parameter estimates of the predictor variables represent approximate point estimates of odds ratio for the presence of each variable, controlling for the effects of all the other variables in the model [8]. Age, age-squared, and body mass index were significant predictors of diabetes. After controlling for the effects of these factors, impaired glucose tolerance made a significant independent contribution to risk, with a parameter estimate of 1.4 , corresponding to an

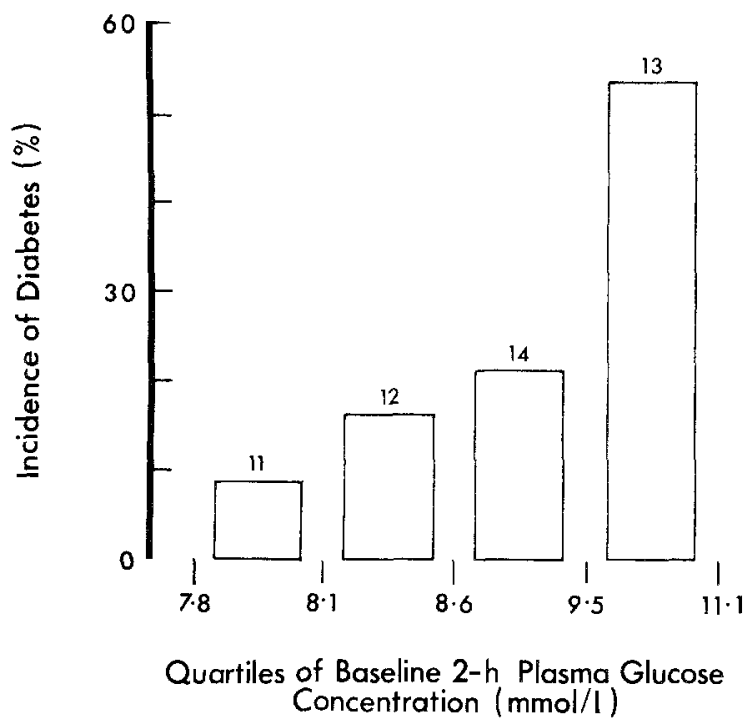

Fig. 1. The incidence of subsequent diabetes during the study period (1975/1976-1982) in the four quartiles of baseline 2-h plasma glucose concentration in subjects with impaired glucose tolerance. The figure above each bar represents the number of individuals in that quartile

odds ratio of 3.6 (95\% confidence interval 1.4-9.1). Impaired glucose tolerance was, in fact, the most significant predictor variable in the model.

\section{Factors associated with progression to diabetes in subjects with impaired glucose tolerance}

To assess which factors were associated with subsequent progression to diabetes in the subjects with impaired glucose tolerance, means of selected physiological, biochemical and environmental factors were compared in those who did, and those who did not, progress to diabetes (Table 4). Continuous variables (other than age) were standardized for age by analysis of covariance. There was a highly significant difference in both mean 2 -h and fasting plasma glucose concentrations between the two groups $(p<0.01)$. Mean body mass index was also significantly higher in those who progressed to diabetes than in those who did not $(p<0.01)$. There was no significant difference in mean triceps skinfold thickness, or in any of the other comparisons. The trend in the proportion of subjects progressing to diabetes across quartiles of baseline plasma glucose concentration is illustrated in Figure 1. Over 50\% of subjects in the highest quartile subsequently developed diabetes.

To assess their independent contribution to the probability of progression to diabetes, the variables examined in a univariate manner in Table 4 were further studied by means of the multiple logistic regression model, predicting development of diabetes (Table 5). Because of problems relating to collinearity, fasting plasma glucose concentration and triceps skinfold thickness were dropped from the analysis. As before, a dummy variable controlled for differences in length of follow-up. 
Table 5. Parameter estimates, standard errors, and standardized parameter estimates for selected variables derived from the multiple logistic regression made predicting progression to diabetes $^{\mathrm{b}}$

\begin{tabular}{lrrc}
\hline Variable & \multicolumn{2}{l}{$\begin{array}{l}\text { Parameter Standard } \\
\text { estimate }\end{array}$} & $\begin{array}{l}\text { Standar- } \\
\text { error } \\
\text { dized } \\
\text { parameter } \\
\text { estimate }\end{array}$ \\
\hline Age (years) & 0.15 & 0.07 & $2.2^{\mathrm{c}}$ \\
Sex (female) & -1.33 & 1.58 & -0.8 \\
Date of first examination & 0.46 & 1.43 & 0.3 \\
2-h plasma glucose $(\mathrm{mmol} / \mathrm{l})$ & 2.52 & 1.06 & $2.4^{\mathrm{c}}$ \\
Body mass index $\left(\mathrm{kg} / \mathrm{m}^{2}\right)$ & 0.22 & 0.11 & 1.9 \\
Plasma cholesterol $(\mathrm{mmol} / \mathrm{l})$ & -1.31 & 1.19 & -1.1 \\
Plasma triglycerides $(\mathrm{mmol} / \mathrm{l})$ & 2.68 & 1.64 & 1.6 \\
Plasma uric acid $(\mathrm{mmol} / \mathrm{l})$ & 11.26 & 11.05 & 1.0 \\
Urinary creatinine $(\mathrm{mmol} / \mathrm{l})$ & -36.23 & 36.59 & -1.0 \\
Systolic blood pressure $(\mathrm{mmHg})$ & -0.11 & 0.06 & $-2.0^{\mathrm{c}}$ \\
Cigarette smoking & -3.00 & 1.62 & -1.9
\end{tabular}

a Log likelihood statistic: 29.4 on 38 degrees of freedom (see Results).

${ }^{b}$ Subjects with impaired glucose tolerance only ( $n=50$, one case deleted due to missing data). ${ }^{c} p<0.05$. The standardized parameter estimate may be referred to tables of the normal distribution as a test of significance of the parameter in the regression equation [8]

The model appeared to fit the data adequately, as shown by the log likelihood statistic of 29 on 38 degrees of freedom. However, as a number of non-significant variables were deliberately retained in the model for consistency with other reports [9-11], maximum precision was not attempted. Age and 2-h plasma glucose concentration were significant predictors of subsequent diabetes in the model. Systolic blood pressure, which was non-significant in the univariate analysis, was a significant negative predictor in the multiple logistic regression model. Conversely body mass index, which was significant in the univariate analysis, just failed to achieve significance in the model. Interaction terms involving the variables of importance were introduced into the model, but none caused a significant improvement. The most significant variable in the final model was 2-h plasma glucose. When 2-h plasma glucose was replaced by the fasting value, plasma glucose concentration remained the most important predictor, though the fit of the model deteriorated slightly.

\section{Discussion}

The introduction of the category of impaired glucose tolerance by the National Diabetes Data Group in 1979 [6], and its adoption by WHO in the following year [1] was in recognition that there were a substantial number of individuals who, though their plasma glucose concentration after a glucose challenge was insufficient to classify them as diabetic, were nevertheless at increased risk of macrovascular disease $[1,6]$. Furthermore, studies suggested that this group, which had hitherto been classified as one of 'latent' or 'borderline' diabetes, had an unpredictable prognosis [1], and the use of the term 'diabetes' was therefore considered unsuitable in this context. Whereas the risk of diabetes was greater in those with impaired glucose tolerance than in normal subjects, a substantial proportion of the former subsequently appeared to revert to normality. This proportion, estimated at $30 \%-50 \%$, was clearly too great to be explained by the phenomenon of regression to the mean, resulting from the known variability of venous plasma glucose concentration.

Three longitudinal studies of impaired glucose tolerance have recently appeared in the literature. These are the Whitehall Study [9] and the Bedford Survey [10], both performed in the United Kingdom, and a sevenyear follow-up study in Osaka, Japan [11]. The results described for Nauruans in this report may thus be compared with contemporary findings from Caucasoid and Japanese populations, providing an opportunity to test for consistency with the results of these studies in an ethnic group previously unstudied with respect to impaired glucose tolerance, and known to suffer a high prevalence of diabetes.

The data from Nauru confirm earlier studies, which have demonstrated that a substantial proportion of subjects with impaired glucose tolerance return to normoglycaemia, but that this group is nevertheless at increased risk of subsequent diabetes. This adds further weight to the notion that impaired glucose tolerance cannot be regarded simply as a pre-diabetic state.

Glucose tolerance is known to be labile, and original mis-classification may account for some of the observed changes of status at an individual level. However, the proportion of subjects with impaired glucose tolerance who subsequently change status (both for better and for worse) seems too great to be explained by this factor alone.

The study has also provided further support for the contention that the strongest predictor of future diabetes in this group is the baseline plasma glucose concentration, and that this association is independent of age and obesity. Obesity has sometimes [10-13], though not invariably $[9,10]$, been related to worsening to diabetes in subjects with impaired glucose tolerance. There appeared to be such an association in Nauruans in our initial univariate analysis, but this lost significance when examined in the multiple logistic regression model.

As previously mentioned, for the sake of consistency with other reports [9-11], all the variables of interest were included in the model presented in Table 5. There are, however, constraints upon the interpretation of a model developed by the unconditional use of a set number of explanatory variables, and when so many redundant variables are retained in the model. When the modelling was repeated using the forward selection procedure, body mass index had a strong effect when entered as the first variable, but lost significance upon the addition of 2-h plasma glucose concentration. Clearly, these two variables are closely related, though plasma glucose was the stronger predictor of subse- 
quent diabetes in both the univariate and the multivariate analysis. However, the role of obesity should not be completely dismissed.

Systolic blood pressure was negatively associated with subsequent diabetes in the full logistic regression model, and also in the forward selection model when controlled for age by a linear term only. However, blood pressure lost significance upon the addition of a squared term for age in the forward selection model. It was not possible to introduce a squared term for age into the full model, due to a limitation of the computer program, but when two non-significant variables were removed (plasma uric acid and creatinine), the squared term for age once again abolished the significance of the blood pressure variable. This suggests that the observed association between blood pressure and subsequent diabetes was due to the confounding effect of age. It is interesting to note that a similar negative association between blood pressure and subsequent diabetes has recently been reported from the Whitehall study [14].

In conclusion, these findings, from a Micronesian population, support reports from the United Kingdom and Japan that impaired glucose tolerance has an unpredictable prognosis, and that, of all the factors studied to date, baseline plasma glucose concentration is the single most important predictor of subsequent diabetes.

Acknowledgements. We are grateful to the Minister for Health, Republic of Nauru for permission to undertake this study. The analysis was carried out with the support of NIH Grant RO1 AM 25446. We thank Ms R. Swan for help in the preparation of the manuscript, Ms V.Collins for data preparation, and the Department of Health, Nauru and the Board of Management of the Royal Southern Memorial Hospital for providing staff and equipment to assist with the survey.

\section{References}

1. WHO (1980) Technical Report Series 646, p 12

2. Ringrose H, Zimmet $P$ (1979) Nutrient intakes in an urbanised Micronesian population with a high diabetes prevalence. Am J Clin Nutr 32: 1334-1341
3. Zimmet P, Taft P, Guinea A, Guthrie W, Thoma K (1977) The high prevalence of diabetes mellitus on a Central Pacific Island. Diabetologia 13:111-115

4. Zimmet P, Arblaster M, Thoma K (1978) The effect of Westernization on native populations. Studies on a Micronesian community with a high diabetes prevalence. Aust NZ J Med 8: 141-146

5. King H, Balkau B, Zimmet P, Taylor R, Raper LR, Borger J, Herriot W (1983) Diabetic retinopathy in Nauruans. Am J Epidemiol 117: 659-667

6. National Diabetes Data Group (1979) Classification and diagnosis of diabetes mellitus and other categories of glucose intolerance. Diabetes 28: 1038-1057

7. Kleinbaum DG, Kupper LL, Morgenstern H (1982) Epidemiologic research. Principles and quantitative methods. Lifetime Learning Publications, Belmont, California

8. Breslow NE, Day NE (1980) Statistical methods in Cancer Research, Volume 1 - the analysis of case-control studies. International Agency for Research on Cancer, Lyon, p 229

9. Jarrett RJ, Keen H, Fuller JH, McCartney M (1979) Worsening to diabetes in men with impaired glucose tolerance ("borderline diabetes'). Diabetologia 16:25-30

10. Keen H, Jarrett RJ, McCartney P (1982) The ten-year follow-up of the Bedford survey (1962-1972): glucose tolerance and diabetes, Diabetologia 22: 73-78

11. Sasaki A, Suzuki T, Horiuchi N (1982) Development of diabetes in Japanese subjects with impaired glucose tolerance: A seven-year follow-up study. Diabetologia 22: 154-157

12. O'Sullivan JB, Mahan CM (1965) Blood sugar levels, glycosuria, and body weight related to development of diabetes mellitus. J Am Med Assoc 194: 117-122

13. O'Sullivan JB, Mahan CM (1968) Prospective study of 352 young patients with chemical diabetes. N Engl J Med 278: 1038-1041

14. Jarrett RJ, Keen H, McCartney P (1982) Worsening to diabetes in persons with impaired glucose tolerance: ten years experience in the Bedford and Whitehall Studies. In: Eschwege E (ed) Advances in diabetes epidemiology. Elsevier Biomedical Press, Amsterdam, New York, Oxford, pp 95-102

Received: 11 April 1983

and in revised form: 18 August 1983

Dr. H. King

WHO Collaborating Centre for the Epidemiology

of Diabetes Mellitus

Royal Southern Memorial Hospital

PO Box 185

South Caulfield

Victoria 3162, Australia 